\title{
Successful Treatment of Primary Sjögren's Syndrome with Chronic Natural Killer Lymphocytosis by High-Dose Prednisolone and Indomethacin Farnesil
}

\author{
Yoshimasa Fujita, Takao Fujii, Naho Takeda, Masao Tanaka and Tsuneyo Mimori
}

\begin{abstract}
We report a patient with Sjögren's syndrome and chronic natural killer lymphocytosis, who developed severe neutropenia, autoimmune hemolytic anemia, and immune thrombocytopenia. High-dose prednisolone therapy improved the hemolytic anemia and thrombocytopenia, but not the CD16 ${ }^{+} \mathrm{CD} 56^{-} \mathrm{NK}$ lymphocytosis completely. Interestingly, indomethacin farnesil (a prodrug of indomethacin) was effective for myalgia and also decreased the number of $\mathrm{CD}^{+} 6^{+} \mathrm{CD} 56^{-} \mathrm{NK}$ cells. NK lymphocytosis is rarely associated with autoimmune disease, but the combination of indomethacin and steroid therapy may have a favorable effect for such patients.
\end{abstract}

Key words: Sjögren's syndrome, chronic natural killer lymphocytosis, indomethacin

(DOI: 10.2169/internalmedicene.46.1881)

Sjögren's syndrome (SS) is a chronic autoimmune inflammatory disease characterized by lymphocytic infiltration of various exocrine organs. In particular, infiltration of the salivary glands and lacrimal glands leads to xerostomia and dry eyes, which are the major symptoms of SS. In SS, natural killer (NK) cells are not usually detected in the salivary glands, lacrimal glands, and other affected organs, while T and B lymphocytes infiltrate these tissues (1). It has been reported that both $\mathrm{NK}$ activity (2) and the $\mathrm{CD} 16^{+} \mathrm{NK}$ cell count (3) are significantly decreased in SS. Here, we present a Japanese woman, who developed SS and chronic NK lymphocytosis (CNKL). While hematological abnormalities such as malignant lymphoma are often detected in patients with SS, disorders of NK cell proliferation have not been reported before. The majority of the NK cells in the present patient showed surface expression of CD16, but not CD56. These cells were suppressed after the initiation of indomethacin farnesil (Infree $\mathrm{S}^{\circledast}$, a prodrug of indomethacin) combined with high-dose steroid therapy.

\section{Case Report}

In July 2002, a 25-year-old Japanese woman was presented to our hospital because of malaise, myalgia, polyar- thralgia, and sicca symptoms. Hematology tests showed autoimmune hemolytic anemia (a hemoglobin concentration of $6.9 \mathrm{~g} / \mathrm{dl}$ and positive Coombs test), thrombocytopenia (a platelet count of $8.2 \times 10^{4} / \mu 1$ and anti-platelet antibody), and severe neutropenia (a neutrophil count of $637 / \mu$ with a total leukocyte count of $9100 / \mu 1)$. She was diagnosed as having primary SS, because of her severe sicca symptoms, positive anti-SS-A/Ro antibodies, abnormalities on salivary gland scintigraphy, and lymphocytic infiltration of salivary gland tissue (Fig. 1). Polyclonal hypergammaglobulinemia was also detected and the $\operatorname{IgG}$ concentration was $3005 \mathrm{mg} / \mathrm{dl}$. She had no clinical manifestations of other rheumatic diseases, such as systemic lupus erythematosus, systemic sclerosis, or rheumatoid arthritis. Antibodies against Sm, U1RNP, SS-B/La, dsDNA, myeloperoxidase, and proteinase 3 were all negative. Abdominal ultrasonography revealed mild splenomegaly. In serological tests for Epstein-Barr virus (EBV), anti-EB VCA and EBNA IgG were positive and anti-EB VCA IgM was negative. Also, EBV DNA quantification using peripheral blood cells demonstrated 0 copy/ug DNA. Large granular lymphocytes were abundant in the peripheral blood smear, and flow cytometric analysis showed that these lymphocytes were $\mathrm{CD} 3 \mathrm{CD}^{-} 6^{+} \mathrm{CD} 56^{-} \mathrm{NK}$ cells (2520/ul) (Fig. 2A). Because the majority of CD3 CD16 


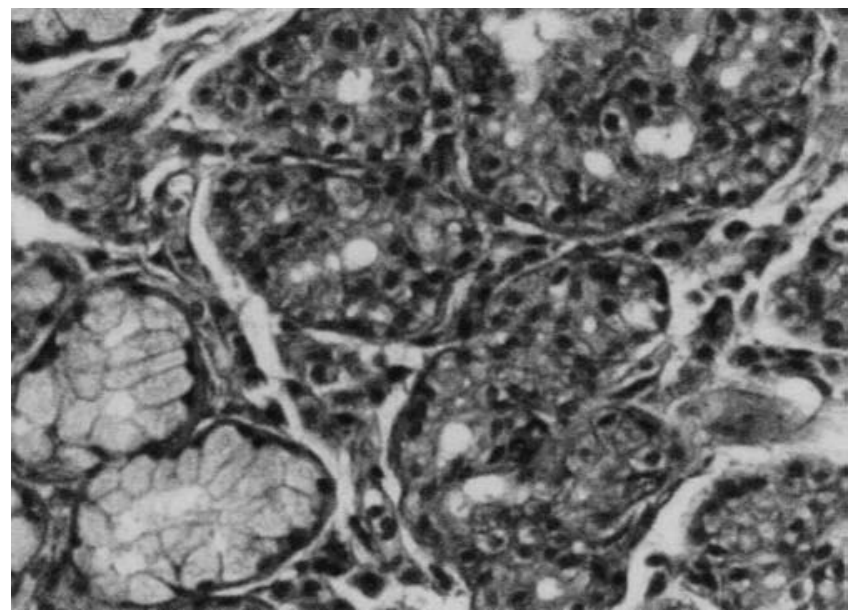

Figure 1. Sialadenitis in our patient with Sjögren's syndrome and chronic NK lymphocytosis $(\times 400)$.

NK cells express CD56 in normal individuals, the number of $\mathrm{CD}^{-} \mathrm{CD}^{-} 6^{+} \mathrm{CD} 56^{-} \mathrm{NK}$ cells in the peripheral blood is

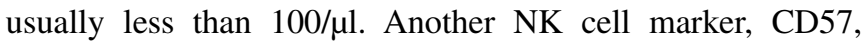
was also expressed in $6.7 \%$ out of total peripheral blood mononuclear cells. Bone marrow examination showed hypercellularity of megakaryocytes, but there were no lymphoma cells. Based on these laboratory data and her clinical course, she was diagnosed as having primary SS accompanied by chronic NK lymphocytosis (CNKL). By immunohistochemistry, $\mathrm{CD} 8^{+} \mathrm{T}$ cells, but not $\mathrm{CD} 16^{+} \mathrm{NK}$ cells, were observed in the salivary glands of our patient (data not shown).

After high-dose prednisolone therapy $(1 \mathrm{mg} / \mathrm{kg}$ daily $)$ was initiated, her hemoglobin increased and the platelet count was normalized. The CD16 ${ }^{+}$CD56 NK cell count also decreased, but was not completely normalized $(916 / \mu 1$, the day 154 after the initiation of steroid treatment, Fig. 3). To control myalgia, she took nonsteroidal anti-inflammatory drugs (NSAIDs) such as indomethacin and meloxicam. However, severe gastrointestinal symptoms occurred when she was using a conventional capsule formulation of indomethacin (Inteban $\mathrm{SP}^{\circledast}$ ), and meloxicam was not effective. Therefore, treatment was switched to indomethacin farnesil (Infree $S^{\circledast}$, $\mathrm{InF}$ ), a prodrug of indomethacin designed to reduce gastrointestinal side effects by esterification of the carboxyl group of indomethacin with farnesol. Interestingly, her myalgia and $\mathrm{CD}^{+} 6^{+} \mathrm{CD} 56 \mathrm{NK}$ cell count $(417 / \mu \mathrm{l})$ were both well controlled after the initiation of InF (the day 377). She stopped taking InF because her myalgia had been completely resolved. Subsequently, the total lymphocytes and the CD16 ${ }^{+}$CD56 NK cell count increased along with recurrence of myalgia $(675 / \mu \mathrm{l})$ (the date 577, Fig. 3). After she commenced InF again, the CD16 ${ }^{+}$CD56 NK cell count was completely normalized (56/ul) and CNKL showed remission. Inteban $\mathrm{SP}^{\circledast}$, which was used between days 65 and 154 after the initiation of steroid, also appeared to have a favorable effects on her NK lymphocytosis. However, meloxicam, which was used between days 154 and 267, might not be effective for lymphocytosis.
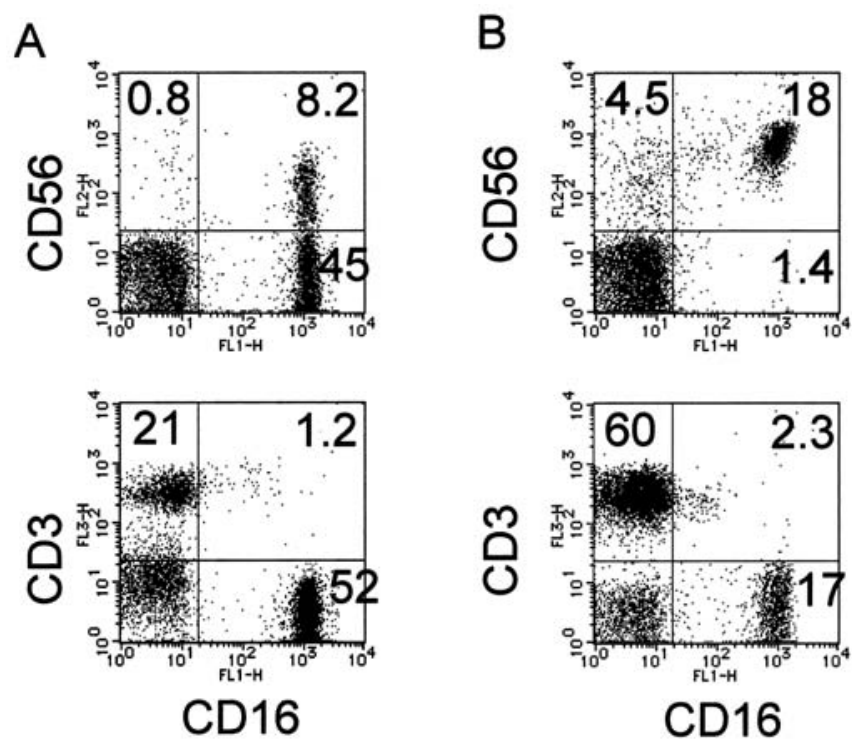

Figure 2. Flowcytometric analysis of peripheral blood mononuclear cells from our patient with Sjögren's syndrome and chronic NK lymphocytosis. Note that the percentage of CD3 $\mathrm{CD}^{-}{ }^{+} \mathrm{CD56}-\mathrm{NK}$ cells is higher in our patient (A) than in a healthy individual (B).

\section{Discussion}

To the best of our knowledge, this is the first case report on a patient with SS and CNKL, although a few cases of large granular lymphocyte syndrome associated with rheumatoid arthritis have been described $(4,5)$. Previously, it was reported that CD16 expression by NK cells was decreased in SS and circulating anti-CD16 antibodies has been recognized in sera from patients with SS (6). However, the immunopathological association between SS and CD16 ${ }^{+} \mathrm{NK}$ cell lymphocytosis was not determined in the present patient, because NK cell infiltration was not observed in the salivary glands.

CNKL is reported to be a relatively rare hematological disorder, and the following diagnostic criteria has been proposed: 1) documentation of absolute lymphocytosis in the peripheral blood for a period at least 6 months, 2) flow cytometric demonstration of the NK cell phenotype, and 3) absence of clinical evidence for NK leukemia/lymphoma (5). Although steroids and/or immunosuppressive drugs such as cyclosporin A have been used for the treatment of CNKL, these agents are not always effective (5, 7-9). NSAIDs are sometimes used to control fever and musculoskeletal pain in CNKL patients, but it has never been reported that NK lymphocytosis was improved by such agents. In the present patient, $\mathrm{InF}$ induced complete remission of CNKL, whereas high-dose steroid therapy partially suppressed CD16 ${ }^{+}$CD56 NK lymphocytosis. Usually, indomethacin upregulates NK cell activity by inhibiting $\mathrm{PGE}_{2}(10,11)$. Oxholm et al reported that this effect of indomethacin on NK cell activity was impaired in SS because the cell membrane composition of essential fatty acids is different from between that in 


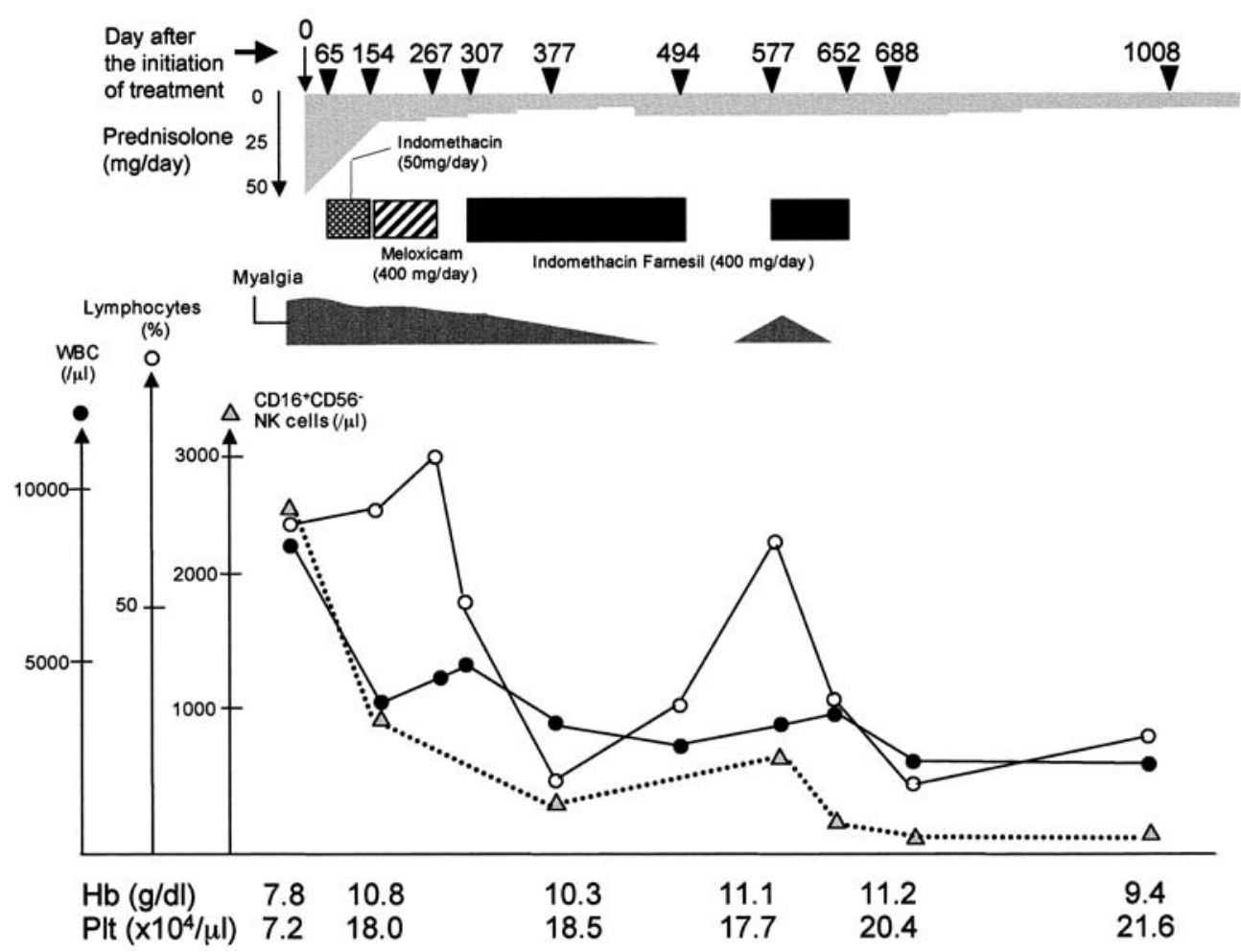

Figure 3. Clinical course of our patient with Sjögren's syndrome (SS) and chronic NK lymphocytosis (CNKL). After the initiation of prednisolone therapy, her hemoglobin and platelet count were normalized. On the other hand, lymphocytosis and the increased $\mathrm{CD}^{+}{ }^{+} \mathrm{CD56}^{-} \mathrm{NK}$ cell count were not well controlled before the concomitant administration of indomethacin farnesil (InF). InF was also effective for myalgia, which might be associated with SS and CNKL. Hb, hemoglobin; PIt, platelet count.

healthy controls (12). We think that not only $\mathrm{InF}$ but also indomethacin (Inteban $\mathrm{SP}^{\circledR}$ ) had a similar favorable effect on NK cell lymphocytosis, such that NK cells of SS patients may show an alternative response to indomethacin. Therefore, we are planning to examine the effect of $\mathrm{InF}$ on $\mathrm{CD} 16^{+}$ CD56 NK cells in vitro and clarify the mechanism by which it suppresses CD16 ${ }^{+}$CD56 $6^{-} \mathrm{NK}$ cell proliferation.

Most cases with CNKL have a clinically indolent course; the disease transforms to NK cell leukemia/lymphoma only in rare cases (13). Granular lymphocytes with CD16 CD56 $^{+}$ CD57 phenotype, which are different from that of the pre- sent case, are reported as a progressive clinical course (14). Recently, Makishima et al have reported that proliferating NK cells in aggressive NK cell leukemia (ANKL) express CXCR1 and CXCR5, but CNKL do not (15). Systemic NK cell migration and transformation to ANKL should be carefully observed in the present patient.

In summary, we reported a patient, who had primary SS accompanied by CD16 ${ }^{+}$CD56 NK lymphocytosis. Although the aggressive treatment for asymptomatic CNKL is not necessary, concomitant therapy with a steroid and indomethacin may be useful for this rare condition.

\section{References}

1. Fox RI, Hugli TE, Lanier LL, Morgan EL, Howell F. Salivary gland lymphocytes in primary Sjogren's syndrome lack lymphocyte subsets defined by Leu-7 and Leu-11 antigens. J Immunol 135: 207-214, 1985.

2. Miyasaka N, Seaman W, Bakshi A, et al. Natural killing activity in Sjögren's syndrome: an analysis of defective mechanisms. Arthritis Rheum 26: 954-960, 1983.

3. Rabbani GR, Phyliky RL, Tefferi A. A long-term study of patients with chronic natural killer cell lymphocytosis. Br J Haematol 106: 960-966, 1999.

4. Ichikawa Y, Yoshida M, Takaya M, et al. Circulating natural killer cells in Sjögren's syndrome. Arthritis Rheum 28: 182-187, 1985.

5. Ozaki M, Kawabe Y, Nakamura H, et al. Elevated serum cytokine levels in a rheumatoid arthritis patient with large granular lympho- cyte syndrome. Rheumatology 40: 592-593, 2001.

6. Saito K, Abe T, Takeuchi T. Decreased Fc $\gamma$ receptor III (CD16) expression on peripheral blood mononuclear cells in patients with Sjögren's syndrome. J Rheumatol 25: 689-696, 1998.

7. Morice WG, Leibson PJ, Tefferi A. Natural killer cells and syndrome of chronic natural killer lymphocytosis. Leuk Lymphoma 41: 277-284, 2001.

8. Tefferi A, Li C-Y, Witzig TE, Dhodapker MV, Okuno SH, Phyliky RL. Chronic natural killer cell lymphocytosis: a descriptive clinical study. Blood 84: 2721-2725, 1994.

9. Bible KC, Tefferi A. Cyclosporin A alleviates severe anaemia associated with refractory large granular lymphocytic leukemia and chronic natural killer cell lymphocytosis. Br J Haematol 93: 406408, 1996. 
10. Malygin AM, Meri S, Timonen T. Regulation of natural killer cell activity by transforming growth factor-beta and prostaglandin $\mathrm{E}_{2}$. Scand J Immunol 37: 71-76, 1993.

11. Rhind SG, Gannon GA, Suzui M, Shephard RJ, Shek PN. Indomethacin inhibits circulating $\mathrm{PGE}_{2}$ and reverses postexercise suppression of natural killer cell activity. Am J Physiol 276: R1496-R1505, 1999.

12. Oxholm P, Pedersen BK, Horrobin DF. Natural killer cell functions are related to the cell membrane composition of essential fatty acids: differences in healthy persons and patients with primary Sjögren's syndrome. Clin Exp Rheumatol 10: 229-234, 1992.
13. Oshimi K. Leukemia and lymphoma of natural killer lineage cells. Int $\mathbf{J}$ Hematol 78: 18-23, 2003.

14. Oshimi $\mathrm{K}$, Yamada $\mathrm{O}$, Kaneko $\mathrm{T}$, et al. Laboratory findings and clinical courses of 33 patients with granular lymphocyte-proliferative disorders. Leukemia 7: 782-788, 1993.

15. Makishima H, Ito T, Asano N, et al. Significance of chemokine receptor expression in aggressive NK cell leukemia. Leukemia 19: 1169-1174, 2005 .

\footnotetext{
(C) 2007 The Japanese Society of Internal Medicine http://www.naika.or.jp/imindex.html
} 